\title{
Osteoporosis Risk Assessment in Postmenopausal Women
}

\author{
Safak Daghan ${ }^{1}$, Asli Kalkim ${ }^{2}$, Gamze Has ${ }^{3}$ \\ ${ }^{I}$ (Assoc.Prof., PhD, RN, Department of Public Health Nursing, Faculty of Nursing / Ege University, Turkey) \\ ${ }^{2}$ (Lecturer, PhD, RN, Department of Public Health Nursing, Faculty of Nursing / Ege University, Turkey) \\ ${ }^{3}$ (Nurse, Siyami Ersek Breast Heart and Vascular Surgery Training and Research Hospital, Turkey)
}

\begin{abstract}
This research is a correlation and descriptive survey conducted in order to determine the risk of osteoporosis in postmenopausal women. Methods: The study were included 322 women aged 45 and above. Data were collected by conducting face to face interview using a questionnaire form developed by the researchers and the osteoporosis risk assessment indices (ORAI and ABONE). The data obtained in the research were evaluated by using SPSS 15.0 for Windows, percentage distribution, correlation analysis, multiple linear regression analysis, chi-square test.

Results: The mean age of the women was $55.78 \pm 9.08$. In terms of osteoporosis, $32 \%$ of the women had intermediate risk and 5\% had high risk according to the ORAI risk assessment index while $26.1 \%$ had risk according to the ABONE risk assessment index. A positive and moderately significant correlation was found between ORAI and ABONE $(r=0.77, p<.001)$.

Conclusion: It is very crucial that nurses determine the osteoporosis risk condition of postmenopausal women and influential factors. It is considered essential that women be provided with training and counseling services as well as changing their lifestyle to reduce osteoporosis risks.
\end{abstract}

Keywords: ABONE, ORAI, Osteoporosis, Postmenopausal

\section{Introduction}

The National Osteoporosis Foundation (NOF) has called osteoporosis the 'silent thief' because bone loss typically occurs without symptoms (National Osteoporosis Foundation, 2008). Osteoporosis poses a significant threat to individuals and public health because of the increased morbidity, mortality and direct and indirect costs associated with fragility fractures (National Osteoporosis Foundation, 2008). It is estimated that more than 200 million people worldwide have osteoporosis (Kutsal, 2009), and that one woman in three and one man in five are at risk of osteoporotic fractures (International Osteoporosis Foundation, 2017). In Turkey, because of prolonged life expectation, osteoporosis and osteoporosis fractures are an important public health problem. In the country as a whole, it has been found in multi-center studies that among the most commonly seen chronic diseases in the aged are osteoarthritis (13.7\%) and osteoporosis (8.2\%) (Beğer \& Yavuzer, 2012).

Osteoporosis is an important problem in women's health, because $80 \%$ of those who suffer this problem are women. According to WHO assessment, osteoporosis is a health problem affecting $30 \%$ of postmenopausal women in the world, and creates a significantly increased risk of fractures. Thus, the lifelong risk of osteoporosis-related fractures in women is nearly $40 \%$, while in men it is only 13\% (Tezcan et al., 2002). Osteoporosis therefore, is not simply a physiological process but one involving risk factors. According to the International Osteoporosis Foundation (IOF), risk factors for osteoporosis include the following: age, female gender, family history, previous fracture, ethnicity, menopause, long term glucocorticoid therapy, rheumatoid arthritis, alcohol, smoking, low body mass index, poor nutrition, vitamin D deficiency, eating disorders, insufficient exercise, low dietary calcium intake and frequent falls (International Osteoporosis Foundation, 2017).

Osteoporosis and osteoporosis-related bone fractures are commonly seen, treatment costs are high and treatment takes a long time. For such reasons, it is necessary to assess people for the risk of osteoporosis. Screening for osteoporosis includes an assessment of clinical risk factors and bone mineral density (BMD) testing (Beatrice et al., 2004). To permit prevention and early intervention, it is therefore important to identify postmenopausal women at risk of developing osteoporosis (Chan et al., 2006). However, BMD testing, which is widely regarded as the gold standard for diagnosing osteoporosis (Chan et al., 2006), is expensive and not universally available, and it can make widespread screening for osteoporosis difficult and impractical (Singer, 2006).

In Turkey unfortunately, cost limitations set by National Health Insurance (NHI) affect the clinical implementation of the BMD test. The NHI will pay the cost of a BMD examination only when associated with endocrinological diseases or non-trauma fractures, or when it is conducted on women over 50 years old or postmenopausal women who are undergoing treatment for osteoporosis. Only three BMD examinations will be 
paid for in a person's lifetime, and the interval between these examinations must exceed one year (Social Security Institution Health Practice Statement, 2013).

In cases where BMD examination cannot be performed, there are various forms which can be used to diagnose risk. The Simple Calculated Osteoporosis Risk Estimation (SCORE) and the Osteoporosis Risk Assessment Instrument (ORAI) are useful indices for determining a patient's risk profile for osteoporosis. SCORE has a sensitivity of $95 \%$ and a specificity $51 \%$ in a 50-year-old woman, and ORAI has a corresponding sensitivity and specificity of $94 \%$ and $32 \%$. Other clinical include ABONE (Age, Body Size, No Estrogen) plus weight criteria, and OSIRIS (Osteoporosis Index of Risk) (Beatrice et al., 2004).

The WHO is moving toward absolute risk assessment and this may help to better identify patients for screening and treatment in the future. Efforts to increase access to BMD testing and improve the sensitivity and specificity of osteoporosis risk assessment instruments may help ensure that individuals with osteoporosis are diagnosed early and receive appropriate treatment to help prevent vertebral and nonvertebral fractures (Singer, 2006). Interest in the use of risk factors arises for three reasons. First, identifying risk factors may be helpful in increasing public awareness of osteoporosis. Second, risk factors can be used as indicators of an individual's susceptibility to develop osteoporosis. Finally, risk factors can be useful in the development and implementation of interventions designed to reduce exposure to these factors by adopting health promoting behaviors (Ailinger et al., 2009).

It is important that health care providers, especially nurses, identify postmenopausal women at risk of developing osteoporosis in order to permit prevention and early intervention. Nurses should make efforts to assist and encourage women to take practical preventative behaviors (Hannon \& Murphy, 2007). The International Osteoporosis Foundation (2002) states that nurses, physiotherapists, dieticians, medical technicians and other health care professionals are often important and trusted contacts, with a key role in informing people about osteoporosis risks and treatment (Horan \& Timmins, 2009).

The objective of this study was to assess the risk of osteoporosis in postmenopausal women and to investigate the relationship between risk assessment indices and their risk factors. Two specific research objectives were formulated:

1. to identify women based on their demographic variables, their osteoporosis risk factors and their osteoporosis risk profile,

2. to detect the factors contributing to their osteoporosis risk profile.

\section{Participants and Procedure}

\section{Methods}

This study was a correlation and descriptive survey conducted at a shopping center located in the city of Izmir, in the western part of Turkey on January - March 2009. The population of the study consisted of women aged 45 and above who were visiting the shopping center. The nonprobability sampling method was used, and for calculation of the sample size, the proportional sampling method was used. In the calculation, the incidence of osteoporosis in postmenopausal women was taken as 30\% (p) as determined by Bozan (2007) and 322 women were included in the research with a $95 \%$ confidence level.

\section{Data Collection}

Data were collected by conducting face-to-face interviews using a questionnaire. The questionnaire consisted of four tools: a demographic characteristics data form, an osteoporosis knowledge and risk factors data form, the Osteoporosis Risk Assessment Instrument (ORAI), and the Age Body Size No Estrogen (ABONE).

The first section of the questionnaire included four questions on demographic information. The second section included 20 questions related to knowledge level about osteoporosis (whether they had heard about osteoporosis or received information and care about osteoporosis, whether they had had a previous bone mineral density test, their current use of an oral calcium or vitamin D supplement) and risk factors for osteoporosis (weight, height, body mass index, loss of height, age at first menarche, year of menopause onset, oral contraceptive use, osteoporosis in the family, prior fractures, smoking, alcohol intake, tea-coffee intake, calcium intake behaviors, exercise behavior, and exposure to the sun).

The ORAI and ABONE indices were used to assess the osteoporosis risk profile of the postmenopausal women. ORAI is a useful index for determining a patient's risk profile for osteoporosis. It was developed by the Canadian Multicenter Osteoporosis Study Center to determine candidates who were suitable for densitometry. The ORAI relies on age, weight, and estrogen replacement therapy to classify women into screen and do not screen categories. ORAI points are given for age: 15 if $\geq 75$ years, 9 if $65-74$ years, and 5 if 55-64 years; weight: 9 points if $<60 \mathrm{~kg}$ and 3 if $60-69.9 \mathrm{~kg}$; and estrogen use: 2 points if not currently taken. ORAI: low risk is indicated by a score of $<9$, moderate risk by a score between 9 and 17 , and a high risk by a score of $>17$ (Aguila et al., 2007). 
ABONE relies on age, weight, and estrogen replacement therapy to classify women into screen and do not screen categories. ABONE points are given for age: 1 if $>65$ years, 0 if $\leq 65$ years; weight: 1 point if $<63.6$ $\mathrm{kg}$ and 0 if $\geq 63.6 \mathrm{~kg}$; and oral contraceptive or estrogen use: 1 point if $\leq 6$ months and 0 if $>6$ months. ABONE: risk is indicated by a score of $\geq 2$; no risk by a score $<2$.

\section{Ethical Consideration}

Women completed questionnaires voluntarily and anonymously; therefore, ethical approval was assumed not to be necessary. The women who agreed to participate in the study were informed about the purpose of the study and their oral consent was received before their inclusion in the research.

\section{Data analysis}

Data were analyzed using SPSS for Windows, version 16.0 (SPSS, Inc., Chicago, IL, USA). Descriptive statistics in terms of percentages, means and SD were used to describe women's demographic characteristics, risk factors and risk profile. Therefore, chi-square tests and Pearson correlation analysis were used to assess associations between risk profile scores and independent variables. Multiple linear regression was used to identify the impacts of independent variables on the women's risk profiles.

\section{Research Limitations}

The current study was limited by the use of convenience sampling. Thus, generalisation of the study findings is weakened. Another limitation of the study is that the data relied on self-reporting by the women.

\section{Results}

\section{Demographic Characteristics and Knowledge About Osteoporosis}

The mean age of the women was 55.78 \pm 9.08 years (min: 45, max: 90). The other demographic characteristics of the women are presented in Table 1. When the women were asked whether they had heard or read about osteoporosis, the majority of them (74.5\%) stated that they had heard of osteoporosis, but a few (19.3\%) had heard nothing at all about the disease. $42.9 \%$ had not received any information or care concerning osteoporosis from a clinic, doctor's office, or health service. More than half of the participants (52.8\%) reported never having previously undergone a bone density measurement examination. Only $16.8 \%$ of the women had used medication for the menopause period, and $85.2 \%$ of them had not used calcium and vitamin D.

\section{Osteoporosis Risk Factors}

Factors that can impact a person's chances of becoming osteoporotic include increased weight, decreased stature, having a family history of osteoporosis, and smoking and alcohol consumption (see Table 2.) Regarding weight and height, it was determined that $17.1 \%$ of the women weighed $60 \mathrm{~kg}$ or below, and $51.9 \%$ were $160-169 \mathrm{~cm}$ in height. Their mean weight and height were $72.18 \pm 12.63 \mathrm{~kg}$ and 161.70 (SD 6.38) cm, respectively, and their mean body mass index (weight/height ${ }^{2}$ ) was calculated to be $27.62 \pm 4.71 \mathrm{~kg} / \mathrm{m}^{2}$ with over $30 \%$ of the women categorized as overweight and $0.9 \%$ as having a low the body mass index.

It was determined that $44.7 \%$ of the women were shorter in height than 10 years previously, $36.3 \%$ had first menstruated above the age of 14 (mean age of menarche $13.05 \pm 1.41$ ), and $30.4 \%$ had been menopausal for over 14 years (mean $8.82 \pm 8.51$ years). Almost $40 \%$ (39.8\%) of the women reported that they had not used any oral contraceptives in the past, while $57.8 \%$ had used oral contraceptives for 1-3 years (mean 5.03 \pm 5.28 years). $35.7 \%$ of the women reported that someone in their family had osteoporosis or had been told that they had osteoporosis, and $60.9 \%$ of these cases were their mothers. It was also determined that $8.4 \%$ of the women had fractures in their spine, hip or wrist area after entering menopause

The women were asked whether they engaged in specific behaviors or habits that were detrimental to bone health. Smoking, alcohol intake, tea-coffee intake, calcium intake behaviors, exercise behaviors and exposure to the sun were assessed. $21.4 \%$ of the women currently smoked cigarettes, and most of these $(85.5 \%)$ smoked one packet of cigarettes per day. $5.9 \%$ of women them currently consumed alcohol. 55.3\% reported that they consumed at least one cup of coffee per day; $95.7 \%$ consumed at least one cup of tea per day, and $32.0 \%$ of the women consumed at least one cup of cola per day. Over two thirds (74.2\%) of the women consumed milk, yogurt and cheese every week; $43.2 \%$ of the women did not drink milk, $24.8 \%$ did not eat yogurt and $13.0 \%$ did not eat cheese every day. Most of the participants (70.2\%) did not exercise regularly (more than three times a week). $36.6 \%$ of the women had no exposure to the sun on a daily basis and nearly $30 \%$ (28.9\%) were exposed to the sun for 5 to 10 minutes per day.

\section{Osteoporosis Risk Profile}

In terms of osteoporosis, $63.0 \%$ of the women were at low risk, $32 \%$ were at intermediate risk and $5 \%$ were at high risk according to the ORAI, while $73.9 \%$ of the women were not at risk, and $26.1 \%$ were at risk 
according to the ABONE risk assessment index (Table 3). A positive and moderately significant correlation was found between ORAI and ABONE $(r=0.77, \mathrm{p}<0.001)$.

\section{Relationships of Independent Variables to Risk Assessment Index}

There was a statistically significant difference between the women's ABONE score and their age $\left(x^{2}=97.35, p<0.001\right)$, body mass index $\left(x^{2}=42.05, p<0.001\right)$, loss of height $\left(x^{2}=11.76, p<0.01\right)$, menopause year $\left(x^{2}=89.43, p<0.01\right)$, use of oral contraceptives $\left(x^{2}=62.11, p<0.01\right)$, tea intake $\left(x^{2}=5.73, p<0.05\right)$ and coffee intake $\left(x^{2}=10.07, p<0.01\right)$. There was no statistically significant difference between the women's ABONE score and age at menarche, family history, breaking a bone after menopause, smoking, alcohol consumption, calcium-rich food consumption, regular exercise or exposure to sunlight.

There was a statistically significant difference between the women's ORAI score and their body mass index $\left(x^{2}=70.57, p<0.001\right)$, loss of height $\left(x^{2}=8.46, p<0.05\right)$, menopause year $\left(x^{2}=135.24, p<0.001\right)$, use of oral contraceptives $\left(x^{2}=10.49, p<0.01\right)$, breaking a bone after menopause $\left(x^{2}=6.31, p<0.05\right)$, tea intake $\left(x^{2}=12.56\right.$, $\mathrm{p}<0.01)$ and coffee intake $\left(\mathrm{x}^{2}=11.04, \mathrm{p}<0.01\right)$. There was no statistically significant difference between the women's ORAI score and age at menarche, family history, smoking, alcohol consumption, calcium-rich food consumption, regular exercise or exposure to sunlight.

\section{Factors Influencing the Women's Osteoporosis Risk Profiles}

The regression models formed by accepting the independent variables of women's body mass index, loss of height, amounts of tea and coffee consumed and history of use of oral contraceptives and the dependent variables of ABONE and ORAI scores were statistically highly significant $(\mathrm{F}$ ABONE $(5,316)=37.71, p<$ $.001 ; \mathrm{F}$ ORAI $(5,316)=24.61, \mathrm{p}<.001)$. These five independent variables explain $37 \%$ of the variation in $\mathrm{ABONE}$ scores and $28 \%$ of the variation in ORAI scores $\left(R^{2}=.37, R^{2}=.28\right)$.

It was found that BMI $(\beta=-.373,|t|=8.17, p<.01)$, loss of height $(\beta=-.171,|t|=3.81, p<.01)$ and oral contraceptive use $(\beta=.457,|\mathrm{t}|=10.07, \mathrm{p}<.01)$ were influential factors in women's ABONE scores.

It was found that BMI $(\beta=-.435,|t|=8.90, p<.01)$, loss of height $(\beta=-.162,|t|=3.35, p<.01)$, amount of coffee consumed $(\beta=-.096,|\mathrm{t}|=1.98, \mathrm{p}<.05)$, amount of tea consumed $(\beta=-.108,|\mathrm{t}|=2.22, \mathrm{p}<.05), \quad$ and oral contraceptive use $(\beta=.198,|t|=4.08, p<.01)$ were influential factors in women's ORAI scores.

The women's body mass index and loss of height had a negative influence on their osteoporosis risk profiles which was statistically significant, while a history of oral contraceptive use had a positive effect on both risk profiles. The amount of tea and coffee consumed had a negative influence but was not statistically significant.

\section{Discussion}

This study explored the risk of osteoporosis in postmenopausal women and the relationships between the risk assessment indices and their risk factors.

\section{Knowledge About Osteoporosis}

A majority of the women $(74.5 \%)$ had heard of osteoporosis; however, approximately one woman in five (19.3\%) had no information about osteoporosis. It was found in a study by Chang et al. 2010 that $81.2 \%$ of women had heard of osteoporosis, but in another study in Turkey (Aksu et al., 2005), 55.7\% of women had no information about osteoporosis. It is necessary that nurses working with this risk group should take every opportunity to give women correct information about osteoporosis. BMD can be safely and effectively measured to diagnose osteoporosis and once a diagnosis is made (Silver et al., 2009). In this research, more than half of the participants (52.8\%) reported never having previously undergone a BMD examination. In a study by Smith et al. (2009) on individuals over the age of 65 , it was found that only $37.4 \%$ had undergone BMD examination (Silver et al., 2009). Calcium and vitamin D intake are traditionally the primary focus for the prevention and management of osteoporosis, both prior and subsequent to DXA screening (McLeod \& Johnson, 2008; McLeod \& Saskatchewan, 2013). However, it was seen in this study that only a small proportion of women (16.8\%) used medication such as calcium and vitamin D in the menopausal period.

\section{Osteoporosis Risk Factors}

The commonest osteoporosis risk factors in the women were found to be excessive tea consumption (95.7\%), coffee consumption (55.3\%), and not taking regular exercise (70.2\%). Similarly, it was found in a study by Chang et al. (2010) that $66 \%$ of women did not take exercise. Taking regular exercise plays a large part in the prevention of osteoporosis. Exercise and walking programs can help build stronger bones and muscles and can be used to increase strength, flexibility and balance (Chan et al., 2005). For this reason, it is important for nurses to inform postmenopausal women of the importance of regular exercise and to encourage them in it. 
It was seen that a very small proportion of the women in the study had a low body mass index. In a study in this country by Peker et al. (2001), this proportion was found to be $2 \%$. Women with a low body mass index are more at risk of osteoporosis than those whose BMI is high. This can be explained by body weight putting greater mechanical pressure on the skeletal system, and at the same time the metabolites of the hormone estrogen synthesized in the fatty tissue ensuring continued mineral density of the bones (Kaplan, 2007).

The risk of fracture of those with a history of fractures is $86 \%$ greater than that of individuals without fractures (IOF, 2017). It was found in the present study that a small proportion of women (8\%) had had incidents of fracture in their spine, hip or wrist area after entering menopause. In a study conducted in this country this proportion was found to be $10-15 \%$ (Peker et al., 2001). This proportion was found to be $37 \%$ by Silver et al. (2009), 24\% by Aguila et al. (2007), 2.5\% by Cass et al. (2006), and 4.9\% by Chan et al. (2005). It is thought that the low proportion found in the present study may be because of the younger age of the women in this study than in other studies.

\section{Osteoporosis Risk Profile}

ORAI and ABONE are accurate and effective osteoporosis risk factor assessment indices. These assessment indices are useful in determining postmenopausal women at high risk of low BMD who should be referred for DXA screening (McLeod \& Johnson, 2008) and high risk individuals with high risk factors for osteoporosis. Christodoulou et al. (2016) found that the highest levels of sensitivity and accuracy in identifying patients at high risk of osteoporosis were obtained by the ORAI (72\%) and the ABONE (65\%). ORAI has successfully indentified over 90\% of women at risk of low BMD in several studies (Cadarette et al., 2001; Gourlay et al., 2005, Gourlay et al, 2008).

ORAI with the should scores indicating medium and high risk of osteoporosis, identified $75 \%$ to $89 \%$ of women, with a consistently reduced cost for public health regarding the usefulness of screening index in alleviating the economic burden of DXA screening. ABONE is an index which is more effective at distinguishing the healthy, and mediumly powerful at selecting the sick. Therefore, while it is effective at providing awareness of osteoporosis risk, it is not useful for DXA. At this point, it is preferable to carry out advanced investigations of osteoporosis in women who are at risk (37\%) by ORAI. It is important to evaluate the women who are identified by ABONE as not at risk (73.9\%) as a priority group for awareness and information under the characteristic of the index as separating the healthy. In a country like Turkey, with limited resources in terms of health services, these results are important for the correct use of the indices and for public health.

Simple risk assessment indices provide a quick and inexpensive way for identifying persons at risk of osteoporosis (Chan et al., 2006). In this study a positive and moderately significant correlation was found between ORAI and ABONE $(r=0.77, p<0.001)$. One study by Rud et al. (2005) investigated the performance of ORAI in a Danish population. The sensitivity of ORAI was 50\%. In a study conducted with Chinese women, Chan et al. (2006) found that ORAI had a sensitivity of $62 \%$ and a specificity of $62 \%$, while the sensitivity of ABONE was $73 \%$ and its specificity was $54.1 \%$. Machado \& Silva, (2008) reported that $26.1 \%$ of women were at risk according to the ABONE risk assessment index. Aguila et al. (2007) found in a study with 665 postmenopausal women that $45 \%$ were at risk, while in a study by Cass et al. (2006) it was found that $66 \%$ were at risk, and BMD was recommended.

ORAI and ABONE were compared with the NOF guidelines with respect to their ability to select younger postmenopausal women ( $>45$ years) for BMD (Singer, 2006). ORAI resulted in $>96 \%$ of women with osteoporosis being referred for testing. ABONE resulted in fewer women with normal BMD being recommended for testing $(<40 \%)$; however, the sensitivity of these instruments was inadequate - only $80 \%$ of women with a BMD T-score of -2.0 would be identified as candidates for BMD (Singer, 2006).

\section{Factors Influencing Women's Osteoporosis Risk Profiles (ABONE and ORAI Scores)}

BMI and loss of height are considered negative influential factors on women's osteoporosis profiles. In a study with postmenopausal African-American women, Wallace et al. (2004) found that the combination of increased age and decreased body weight were risk factors strongly associated with low BMD. A history of oral contraceptive use had a positive effect on both risk profiles.

\section{Conclusion}

The purpose of this study was to investigate how well the simple clinical decision rules of ORAI and ABONE relate to osteoporosis risk factors of postmenopausal women. Such knowledge has the potential to help health professionals with these easy-to-use rules in fracture prediction independent of patients' BMD scores. It is crucial that nurses determine the osteoporosis risk profile of postmenopausal women and the risk factors. It is considered essential that women be provided with training and counseling services as well as changing their lifestyle to reduce osteoporosis risks. 
Health care professionals, who emphasize primary, secondary and tertiary prevention with individuals and families, should develop effective prevention strategies for women with osteoporosis risks to protect the health of these vulnerable populations which are at risk of osteoporosis. A conclusion section must be included and should indicate clearly the advantages, limitations, and possible applications of the paper. Although a conclusion may review the main points of the paper, do not replicate the abstract as the conclusion. A conclusion might elaborate on the importance of the work or suggest applications and extentions.

\section{References}

[1] D.M. Aguila, C. Gomez-Vaquero, A. Rozadilla, M. Romera, J. Narvaez, and J.M. Nolla, Decision rules for selecting women for bone mineral density testing: Application in postmenopausal women referred to a bone densitometry unit. J Rheumatol, 34, 2007, 1307-1312.

[2] R.L. Ailinger, M.A. Braun, H. Lasus, and K. Whitt, Factors influencing osteoporosis knowledge: A community study, Journal of Community Health Nursing, 22(3), 2009, 135-142.

[3] A. Aksu, M. Zinnuroğlu, B. Karaoğlan, S. Akın, Y.G. Kutsal, F. Atalay, and G. Dinçer, Osteoporoz, eğitim durumu ve farkındalık düzeyi araștırma sonuçları. Osteoporoz Dünyasından, 11, 2005, 36-40.

[4] J. Beatrice, M.D. Edwards, R. Ellen, D. Brooks, B. Craig, and M.D. Langman, Osteoporosis screening of postmenopausal women in the primary care setting: A case-based approach. Gender medicine, 1(2), 2004, 70-85.

[5] T. Beğer and H. Yavuzer, Yaşlılık ve yaşlılık epidemiyolojisi. Klinik Gelişim, 25, 2012, 1-3.

[6] B. Bozan, Postmenopozal Osteoporozda Egzersiz Eğitiminin Etkisi, Dokuz Eylül Üniversitesi Sağlık Bilimleri Enstitüsü Fizik Tedavi ve Rehabiltasyon Anabilim Dalı Fizik Tedavi ve Rehabilitasyon Doktora Programı Doktora Tezi, İzmir, 2007.

[7] S.M. Cadarette, S.B. Jaglal, T.M. Murray, J. Warren, L.J. McIsaac, and P.B. Jacques, Evaluation of decision rules for referring women for bone densitometry by Dual-Energy X-ray Absorptiometry. JAMA, 286(157), 2001, 57-63.

[8] A.R. Cass, A.J. Shepherd, C.A. Carlson, Osteoporosis risk assessment and ethnicity: Validation and comparison of clinical risk stratification instruments. J Gen Intern Med, 21, 2006, 630-635.

[9] M.F. Chan, C.Y. Ko, and M.C. Day, The effectiveness of an osteoporosis prevention education programme for women in Hong Kong: A randomized controlled trial. Journal of Clinical Nursing, 14, 2005, 1112-1123.

[10] S.P. Chan, C.C. Teo, S.A. Ng, N. Goh, C. Tan, and M. Deurenberg-Yap, Validation of various osteoporosis risk indices in elderly Chinese females in Singapore. Osteoporos Int., 17, 2006, 1182-1188.

[11] S.F. Chang, R.S. Yang, U.L. Chung, C.M. Chen, M.H. Cheng, Perception of risk factors and DXA T score among at-risk females of osteoporosis. Journal of Clinical Nursing, 19, 2010, 1795-1802.

[12] S. Christodoulou, G.I. Drosos, A. Ververidis, A. Galanos, G. Anastassopoulos, K. Kazakos, Risk assessment instruments for screening bone mineral density in a Mediterranean population, World J Orthop, 18; 7(9), 2016, 577-583.

[13] M.L. Gourlay, W.C. Miller, F. Richy, J.M. Garrett, L.C. Hanson, and J.Y. Reginster, Performance of osteoporosis risk assessment tools in postmenopausal women aged 45-64 years. Osteoporosis International, 16(8), 2005, 921-927.

[14] M.L. Gourlay, J.M. Powers, L.Y. Lui, and K.E. Ensrud, Clinical performance of osteoporosis risk assessment tools in women aged 67 years and older. Osteoporosis International, 19(8), 2008, 1175-1183.

[15] C. Hannon and K. Murphy, A survey of nurses' and midwives' knowledge of risks and lifestyle factors associated with osteoporosis. Journal of Orthopaedic Nursing, 11, 2007, 30-37.

[16] A. Horan and F. Timmins, The role of community multidisciplinary teams in soteoporosis treatment and prevention. Journal of Orthopaedic Nursing, 13, 2009, 85-96.

[17] International Osteoporosis Foundation. Osteoporosis. [cited 2017 February 10]. Available from: www.iofbonehealth.org/.

[18] S. Kaplan, Postmenopozal osteoporozda risk faktörleri ve korunma yolları. Fırat Sağlık Hizmetleri Dergisi, 2(4), $2007,23-31$.

[19] Y.G. Kutsal, Osteoporosis: The situation in Turkey and the World, Türkiye Klinikleri J Gynecol Obst-Special Topics, 2(3), 2009, 111.

[20] P. Machado and J.A.P. da Silva, Performance of decision algorithms for the identification of low bone mineral density in Portuguese postmenopausal women. Acta Reumatol 33, 2008, 314-328.

[21] K.M. McLeod and S.C. Johnson, Identifying women with low bone mass: A systematic review of screening tools. Geriatric Nursing, 30(3), 2008, 164-173.

[22] K.M. McLeod and R. Saskatchewan, Osteoporosis care gap, doctoral diss., Kinesiology and Health Studies University of Regina, 2013.

[23] National Osteoporosis Foundation, Osteoporosis: review of the evidence for prevention, diagnosis and treatment and cost effectiveness analysis, status report. National Osteoporosis Foundation, Washington, DC, 2008.

[24] Ö. Peker, Ö. El, S. Gülbahar, A. Akalın, S. Öncel, and Y. Gökçe-Kutsal, Farklı sosyoekonomik düzeydeki postmenopozal kadınlarda kemik mineral yoğunluğunun değerlendirilmesi ve risk faktörlerinin belirlenmesi. Assessment of bone mineral density in postmenopausal women with different socioeconomic status and evaluation of risk factors in osteoporosis. Ege Fiz Tip Reh Der, 7(3-4), 2001, 105-112.

[25] B. Rud, J.E. Jensen, L. Mosekilde, S.P. Nielsen, J. Hilden, and B. Abrahamsen. Performance of four clinical screening tools to select peri- and early postmenopausal women for dual X-ray absorptiometry. Osteoporosis International, 16(7), $2005,764-772$.

[26] J.S. Silver, C. Inderjeeth, and G. Lewin, Research osteoporosis risk in a home care setting. Australasian Journal on Ageing, 28(2), 2009, 75-80

[27] A. Singer, Osteoporosis diagnosis and screening clinical cornerstone. Management of Osteoporosis, 8(1), 2006, 9-18.

[28] Social Security Institution, Health Practice Statement, 2013. http://www.resmigazete.gov.tr/eskiler/2013/03/20130324-3.pdf

[29] S. Tezcan, N. Subaşı, and H. Altıntaş, Ankara'nın iki bölgesindeki 40 yaş ve üzeri kadınlar ile bazı okullardaki kadın öğretmenlerde osteoporoz bilgi düzeyi ve risk faktörü sıklığı. Osteoporoz Dünyasından, 8(4), 2002, 161-168.

[30] L.S. Wallace, J.E. Ballard, D. Holiday, L.W. Turner, A.J. Keenum, and C.M. Pearman Evaluation of decision rules for identifying low bone density in postmenopausal African-American women. J Natl Med Assoc, 96, 2004, 290-296. 
Table 1. Demographic Characteristics of Women $(n=322)$

\begin{tabular}{|l|l|l|}
\hline Characteristic & $\mathbf{n}$ & \% \\
\hline Age (years) & & \\
$45-54$ & 179 & 55.6 \\
$55-64$ & 85 & 26.1 \\
$65-74$ & 42 & 13.0 \\
$75+$ & 17 & 5.3 \\
\hline Marital status & & \\
Married & 227 & 70.5 \\
Single & 95 & 29.5 \\
\hline Education & & \\
Primary or below & 192 & 59.6 \\
Secondary & 99 & 30.7 \\
College or above & 31 & 9.6 \\
\hline Ocupation & & \\
Blue-collar & 52 & 16.1 \\
White-collar & 34 & 10.6 \\
Housewife & 187 & 58.1 \\
Retired & 49 & 15.2 \\
\hline Total & 322 & 100.0 \\
\hline
\end{tabular}

Table 2 Osteoporosis Risk Factors of Women $(n=322)$

\begin{tabular}{|l|l|l|}
\hline Risk Factors & n & \% \\
\hline 60 weight -below (kg) & 55 & 17.1 \\
Low BMI (<18.5 kg/m $\left.{ }^{2}\right)$ & 3 & 0.9 \\
Loss Of Height (Before 10 years) & 144 & 44.7 \\
Age of menarche (14 years above) & 117 & 36.3 \\
Menopause year (11 years and above) & 98 & 30.4 \\
No using oral contraceptive & 128 & 39.8 \\
Family history of osteoporosis & 115 & 35.7 \\
Broken a bone after menopausal & 27 & 8.4 \\
Current smoker & 69 & 21.4 \\
Alcohol consumption & 19 & 5.9 \\
Tea intake & 308 & 95.7 \\
Coffee intake & 178 & 55.3 \\
Low calcium-rich foods consumption & 83 & 25.8 \\
No regularly exercise & 226 & 70.2 \\
Avoidance of sun exposure & 118 & 36.6 \\
\hline
\end{tabular}

Table 3. ORAI and ABONE Scores of Women $(n=322)$

\begin{tabular}{|l|l|l|}
\hline Risk Index & n & \% \\
\hline ORAI & & \\
Low risk & 203 & 63.0 \\
Intermediate risk & 103 & 32.0 \\
High risk & 16 & 5.0 \\
\hline ABONE & & \\
No risk & 238 & 73.9 \\
Had risk & 84 & 26.1 \\
\hline Total & 322 & 100.0 \\
\hline
\end{tabular}

Table 4. Summary of Multiple Regression Analyses for Influential Factors on Women's Osteoporosis Risk Profile with ABONE and ORAI $(\mathrm{n}=322)$

\begin{tabular}{|c|c|c|c|c|c|c|}
\hline & \multicolumn{3}{|c|}{ ABONE } & \multicolumn{3}{|c|}{ ORAI } \\
\hline Variable & B & SH & $\boldsymbol{\beta}$ & B & SH & $\boldsymbol{\beta}$ \\
\hline BMI & -.210 & .026 & -.373 & -.327 & .037 & -.435 \\
\hline Loss of Height & -.151 & .040 & -.171 & -.190 & .057 & -.162 \\
\hline Coffee intake & -.078 & .040 & -.088 & -.114 & .057 & -.096 \\
\hline Tea intake & -.068 & .062 & -.050 & -.197 & .089 & -.108 \\
\hline Using oral contraceptive & .410 & .041 & .457 & .238 & .058 & .198 \\
\hline$R^{2}$ & & .37 & & & .28 & \\
\hline$F$ & & $37.71 *$ & & & $24.61 *$ & \\
\hline
\end{tabular}

$* p<.001$ 